\title{
Cuticle hydrocarbons in saline aquatic beetles
}

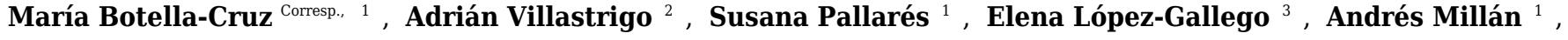 \\ Josefa Velasco ${ }^{1}$ \\ 1 Department of Ecology and Hydrology, Universidad de Murcia, Spain \\ 2 Institute of Evolutionary Biology (CSIC-Universitat Pompeu Fabra), Barcelona, Spain \\ 3 Instituto Murciano de Investigación y Desarrollo Agrario y Alimentario (IMIDA), Murcia, Spain \\ Corresponding Author: María Botella-Cruz \\ Email address: maria.botella1@um.es
}

Hydrocarbons are the principal component of insects cuticle and play an important role in maintaining water balance. Cuticular impermeability could be an adaptative response to salinity and desiccation in aquatic insects; however, cuticular hydrocarbons have been poorly explored in this group and there are no previous data on saline species. We characterized cuticular hydrocarbons of adults and larvae of two saline aquatic beetles, namely Nebrioporus baeticus (Dytiscidae) and Enochrus jesusarribasi (Hydrophilidae), using a gas chromatograph coupled to a mass spectrometer. The $\mathrm{CHC}$ profile of adults of both species, characterized by a high abundance of branched alkanes and low of unsaturated alkenes, seems to be more similar to that of some terrestrial beetles (e.g. desert Tenebrionidae) compared with other aquatic Coleoptera (freshwater Dytiscidae). Adults of $E$. jesusarribasi had longer chain compounds than N. baeticus, in agreement with their higher resistance to salinity and desiccation. The more permeable cuticle of larvae was characterized by a lower diversity in compounds, shorter carbon chain length and a higher proportion of unsaturated hydrocarbons compared with that of the adults. These results suggest that osmotic stress on aquatic insects could exert a selection pressure on $\mathrm{CHC}$ profile similar to aridity in terrestrial species. 


\section{CUTICLE HYDROCARBONS IN SALINE AQUATIC BEETLES}

María Botella-Cruz ${ }^{1}$, Adrián Villastrigo ${ }^{2}$, Susana Pallarés ${ }^{1}$, Elena López-Gallego ${ }^{3}$, Andrés Millán ${ }^{1}$ and Josefa Velasco ${ }^{1}$

${ }^{1}$ Department of Ecology and Hydrology, University of Murcia, Murcia, Spain

${ }^{2}$ Institute of Evolutionary Biology (CSIC-Universitat Pompeu Fabra), Barcelona, Spain

${ }^{3}$ Instituto Murciano de Investigación y Desarrollo Agrario y Alimentario (IMIDA), Murcia, Spain

\section{Corresponding author:}

María Botella-Cruz

maria.botella1@um.es

Department of Ecology and Hydrology, Campus de Espinardo, University of Murcia, 30100, Murcia, Spain.

$+34868884977$ 


\section{Abstract}

2 Hydrocarbons are the principal component of insects cuticle and play an important role in

3 maintaining water balance. Cuticular impermeability could be an adaptative response to salinity

4 and desiccation in aquatic insects; however, cuticular hydrocarbons have been poorly explored in

5 this group and there are no previous data on saline species. We characterized cuticular

6 hydrocarbons of adults and larvae of two saline aquatic beetles, namely Nebrioporus baeticus

7 (Dytiscidae) and Enochrus jesusarribasi (Hydrophilidae), using a gas chromatograph coupled to

8 a mass spectrometer. The CHC profile of adults of both species, characterized by a high

9 abundance of branched alkanes and low of unsaturated alkenes, seems to be more similar to that

10 of some terrestrial beetles (e.g. desert Tenebrionidae) compared with other aquatic Coleoptera

11 (freshwater Dytiscidae). Adults of E. jesusarribasi had longer chain compounds than N. baeticus,

12 in agreement with their higher resistance to salinity and desiccation. The more permeable cuticle

13 of larvae was characterized by a lower diversity in compounds, shorter carbon chain length and a

14 higher proportion of unsaturated hydrocarbons compared with that of the adults. These results

15 suggest that osmotic stress on aquatic insects could exert a selective pressure on CHC profile 16 similar to aridity in terrestrial species. 
Maintaining water balance is critical for insects survival, especially in arid and semi-arid regions

(Addo-Bediako et al., 2001; Gibbs et al., 2003). This is true not only for terrestrial, but also for aquatic species which may be periodically exposed to dry conditions during seasonal droughts and dispersal events. Insects in saline waters are also exposed to hyperosmotic stress which alters water and ionic homeostasis (Bradley, 2009). Therefore, saline water insects in arid regions are challenged with contrasting osmotic gradients from the aquatic and the aerial environment. Managing water loss under such stressful conditions is a critical problem for aquatic insects, as they are thought to be more permeable to water than their terrestrial counterparts (Beament et al., 1961).

Among the diverse ways to minimize water loss in terrestrial insects, the control of cuticle permeability is one the most important mechanisms (Chung \& Caroll, 2015; Rajpurohit et al., 2017), but its role in aquatic ones has been less explored (e.g. Jacob \& Hanssen, 1986; Alarie et al., 1998). The epicuticle of insects is covered with complex mixtures of nonpolar and polar compounds (Gołębiowski et al., 2008), being hydrocarbons the principal hydrophobic compounds of this layer, representing in some cases more than $90 \%$ of the cuticle (Hadley, 1977; Malinski et al., 1986). Insect cuticular hydrocarbons (CHCs) are thought to represent a primary adaptation to desiccation imposed by the transition to a terrestrial existence (Jallon et al., 1997). CHCs are exceptionally diverse and include complex mixtures of straight-chain compounds (nalkanes), branched alkanes and unsaturated compounds (Lockey, 1988). Increases in the amount of CHCs or changes in their chemical composition resulting in increased chain length, linearity, and saturation are the main means of minimizing cuticular transpiration in insects (Benoit, 2010; 
41 Rajpurohit, 2010; Savkovic et al., 2012), these are also involved in other important functions, 42 such as protecting insects from microorganisms (Stiziano et al., 2015), chemical communication

43 for recognition between closely related taxa (e.g. Howard \& Blomquist, 2005; Billeter et al., 44 2009; Savkovic et al., 2012; Pattanayak et al., 2014; Zhang et al., 2014), sexual recognition 45 (Carlson et al., 1971; Jacobs \& Hanssen, 1986) or signalling of age and individual reproductive 46 status (Cuvillier-Hot et al., 2001). CHCs with chain lengths ranging from approximately 21 to 50 47 carbons are usually related to cuticular permeability, while those with fewer than 21 carbons 48 (volatile compounds) are involved in other functions (Chung \& Caroll, 2015), such as pheromones or defensive compounds (Blomquist \& Bagnères, 2010). Characterization of insect CHCs may therefore provide valuable information on many aspects of insect physiology and 51 ecology.

$52 \mathrm{CHC}$ profiles are shaped by phylogenetic constraints; for example, $\mathrm{CHCs}$ in Coleoptera display common features at superfamily or family levels reflecting evolutionary tendencies (Jacobs \& Hanssen, 1986). However, the amount and composition of CHCs also shows an important variation between species and populations reflecting local adaptation and it is strongly associated with desiccation resistance (Gibbs et al., 1997; Kwan \& Rundle, 2010). For example, in desert Tenebrionids, the specific profile of $\mathrm{CHC}$, characterized by high proportions of long chain lengths of branched alkanes, is thought to be a physiological adaptation to aridity (Hadley, 1978; Lockey, 1980). Similarly, CHC profiles varied predictably in populations of Drosophila melanogaster based on known associations between chain length, environmental variables and ecological function (Rajpurohit et al., 2017). In aquatic insects, salinity could exert a selective pressure on CHCs so that saline species could be expected to have a higher relative abundance of long-chain CHCs (higher impermeability) than freshwater ones. However, most studies on $\mathrm{CHC}$ 
64 composition and their functions have been carried out on terrestrial insects (e.g. Blomquist \& 65 Jackson, 1979; Lockey, 1980; Alabi et al., 2011; Pattanayak et al., 2014; Stiziano et al., 2015, 66 Rajpurohit et al., 2017), whereas among aquatic ones, CHC profiles have only been described for 67 some freshwater dytiscids (Jacob \& Hanssen, 1986; Alarie et al., 1998). On the other hand, CHCs show a significant degree of plasticity conferring a notable intraspecific variability (Howard \& Blomquist, 1982; Gibbs \& Rajpurohit 2010). Many studies have reported differences in $\mathrm{CHC}$ profiles within species depending on sex (e.g. Beran et al., 2014; Pattanayak et al., 2014), developmental stage (e.g. Bagnères et al., 1996), the feeding state of individuals (e.g. Jacob \& Hanssen, 1986; Alabi et al., 2011), environmental conditions (Toolson 1982) or rearing temperature (e.g. Rouault et al., 2004; Rajpurohit et al., 2017).

In inland saline waters, Coleoptera is one of the most representative and diverse insect orders (Millán et al., 2011) and, therefore, have been recently used as model organisms to study physiological tolerances to the main natural stressors in these systems, i.e. temperature, salinity and desiccation (e.g. Sánchez-Fernández et al., 2010; Pallarés et al., 2012; Céspedes et al., 2013; Pallarés et al., 2016). However, the potential role of cuticle permeability in driving stress tolerance in water beetles is unknown.

The aim of this study was to characterize CHC profiles of two saline water beetles representative of two of the most common families of Coleoptera in inland waters, Nebrioporus baeticus (Schaum) (family Dytiscidae, suborder Adephaga) and Enochrus jesusarribasi Arribas \& Millán (family Hydrophiliade, suborder Polyphaga). Specifically, we address the following questions: 1) Do CHC profiles of saline water beetles show similar or different patterns to those found in other aquatic Coleoptera?, 2) Do CHC profiles differ between the two studied species? and 3) Do CHCs show intraspecific variation in relation to sex and life stage within the studied species? 
87 Because longer chain-length $\mathrm{CHCs}$ are thought to be more effective at preventing water loss

88 (Gibbs, 1998), we expected a higher proportion of these compounds in i) the two saline studied

89 species compared with freshwater ones, ii) the most halotolerant of the studied species $(E$.

90 jesusarribasi, see Material and methods section), iii) adults compared with larvae in both studied

91 species.

\section{Materials and methods}

93

94

\section{Study species, specimens collection and maintenance}

4 The studied species belong to two distant lineages of beetles (suborders Polyphaga and Adephaga) that have successfully colonized saline waters, showing a high osmoregulatory ability across a wide range of salinities (Pallarés et al., 2015). Adults of the most halotolerant species,

E. jesusarribasi, are crawling, herbivorous and usually found in the shallow margins of hypersaline water bodies, while those from $N$. baeticus inhabit mesosaline waters and are active diving predators (Millán et al., 2014). Larvae of both species are benthic, carnivorous and desiccation-sensitive. Flying adults are the main source of colonizers during seasonal droughts.

Adults and larvae (second and third stages) specimens of $N$. baeticus and E. jesusarribasi were collected from typical localities in SE Spain in October 2015, where they constitute highly abundant populations, namely Chícamo stream (mean conductivity: $20 \mathrm{mS} \mathrm{cm}^{-1}$ ) and Rambla Salada stream (mean conductivity: $84 \mathrm{mS} \mathrm{cm}_{-}{ }^{1}$ ) with the collection permission number 201600150115 from the Consejeria de Agua, Agricultura y Medio Ambiente, Región de Murcia. Adults and larvae of each species were separately maintained in the laboratory for $48 \mathrm{~h}$ at $20^{\circ} \mathrm{C}$ in $4 \mathrm{~L}$ aquaria containing water and substrate from the collection site. 
109 Prior to $\mathrm{CHC}$ extraction, individuals of both life stages were killed by freezing at $-20^{\circ} \mathrm{C}$ in glass

110 vials. CHCs of adult males $(\mathrm{n}=10)$, females $(\mathrm{n}=10)$ and larvae of each species $(\mathrm{n}=10$ for $N$.

111 baeticus and $\mathrm{n}=16$ for $E$. jesusarribasi) were extracted individually in $2 \mathrm{~mL}$ vials by submerging

112 each specimen into $175 \mu \mathrm{L}$ of n-hexane containing $10 \mathrm{ng} \mu \mathrm{L}_{-}{ }^{1}$ of octadecane $\left(\mathrm{C}_{18}\right)$ as an internal

113 standard (e.g. Kwan \& Rundle, 2010; Stiziano et al., 2015). Vials were continuously stirred for 5

$114 \mathrm{~h}$ at $20^{\circ} \mathrm{C}$. The lipid extract was placed in borosilicate glass microinserts and evaporated and

115 concentrated to dryness under a gentle stream of gas nitrogen. The residue was dissolved in 20

$116 \mu \mathrm{L}$ of hexane and ultrasonicated for 2 min (e.g. Gołębiowski et al., 2011; Savkovic et al., 2012).

117 After $\mathrm{CHC}$ extraction, adults were sexed by examining genitalia in a stereomicroscope (Leica

118 M165C with a Leica MEB10 fibre optic illuminator).

119 CHCs were identified and quantified by gas chromatography-mass spectrometry (GC-MS) using 120 a 7890B GC system (Agilent Technologies, CA, USA) and 5977 MSD (Network Mass selective 121 Detector (MS) fitted with a HP-5 phenylmethyl siloxane column of $30 \mathrm{~m} \times 250 \mu \mathrm{m} \times 0.25 \mu \mathrm{m}$ a 122 pulsed split less inlet (at $250^{\circ} \mathrm{C}$ ). The temperature program began at $70^{\circ} \mathrm{C}$, ramping at $30^{\circ} \mathrm{C}$ $123 \min _{-}{ }^{1}$ to $200^{\circ} \mathrm{C}$, slowing to $5^{\circ} \mathrm{C} \min _{-}{ }^{1}$ to $310^{\circ} \mathrm{C}$, then ramping at $120^{\circ} \mathrm{C}$ min $-^{1}$ to $310^{\circ} \mathrm{C}$ and 124 holding for $5 \mathrm{~min}$.

125 The basic characterization of CHC structures was conducted by interpreting their EI mass spectra 126 (number of carbons, methyl branching in saturated chains and double bonds in unsaturated 127 chains). $\mathrm{N}$-alkanes were identified by comparison of retention times with n-alkane standards 128 (C10 - C40, Sigma Aldrich). Branched alkanes and unsaturated compounds were identified by 129 comparing the Kovats index (KI) with those of known compounds and by comparison of mass 130 spectra using the NIST5 library. 
131 Adjustments were made to peak time based on the time and area of the octadecane standard (e.g.

132 Arcaz et al., 2016). Relative abundance of each $\mathrm{CHC}$ was expressed as the proportion of its

133 adjusted peak area on the total adjusted areas (the sum of the adjusted areas of all the CHCs).

134 The absolute amount of each compound was calculated according to the known amount of

135 octadecane present within the sample based on the area under the GC peak. The amount of total

$136 \mathrm{CHCs}$ of each specimen was then stimated as the sum of the abundance of all the CHCs.

137 Data analysis

138 Inter and intraspecific differences on cuticular profiles were examined by means of Principal 139 Components Analysis (PCA), performed with the R package FactoMineR. For adults, scores for 140 the first three PCA factors were used as dependent variables in a multivariate analysis of 141 variance (MANOVA) to test for differences in CHC profiles between species and sexes. The 142 interaction term was included to assess whether sex-specific differences in CHC composition 143 were consistent between the two species. CHC profiles of larvae were compared between species 144 using ANOVA and the first PCA factor scores as the dependent variable. Differences in the 145 relative abundance of the major classes of $\mathrm{CHC}$ compounds (i.e. n-alkanes, branched alkanes 146 (methyl-alkanes and other branched alkanes) and unsaturated compounds) between species, 147 stages and sexes were also assessed by ANOVAs.

148 Relative abundance data were arcsine square-root transformed for analyses. Normality and 149 homocedasticity assumptions were validated on model residuals by graphical inspection (plots of 150 residuals versus fitted values and $Q-Q$ plots) (Zuur et al., 2009). Because CHCs $\leq 20 \mathrm{C}$ and $151 \mathrm{CHCs}>20 \mathrm{C}$ are involved in different biological functions, these analyses were made separately 152 for each group. All statistical analyses were performed in R studio version 0.99 .896 . 


\section{Results}

\section{Overall CHC profiles}

155 The total number of CHCs in adults of N.baeticus was 57 for males and 50 for females. In $E$. 156 jesusarribasi, 46 CHCs were identified in males and 56 in females. The longest chain length

$157 \mathrm{CHC}$ of adults of E. jesusarribasi was hexatriacontane (36C), while that of $N$. baeticus was 158 shorther (31C), corresponding to tritriacontane. Larvae of both species had a lower number of $159 \mathrm{CHC}$ compounds than adults (25 in N. baeticus and 20 in E. jesusarribasi) and the former had 160 shorter chain lengths. CHC length of larvae of both species ranged from 14 to 24 carbon atoms, 161 the longest $\mathrm{CHC}$ being an unidentified branched alkane in N. baeticus and an unidentified 162 unsaturated $\mathrm{CHC}$ in E. jesusarribasi (see Table $\mathrm{S} 1$ for specific information of CHC compounds). 163 The total amount of CHCs was also higher in adults of both species than larvae life stage (Table $164 \mathrm{~S} 1)$.

165 The most abundant CHC in adults was a brached alkane compound in both species. In $N$. 166 baeticus, it was an undeterminated one (25C) in males and the 4-methyl pentacosane in females 167 (25C), while in E. jesusarribasi it was n-dimethyl tritriacontane (33C) in both sexes. In larvae, 168 the most abundant compound was docosene (22C) in N. baeticus and octadecene (18C) in E. 169 jesusarribasi, both unsaturated CHCs (Table S1).

170 The PCA returned two principal factors that explained $32.65 \%$ and $9.94 \%$ of the total variance in 171 adults and $46.83 \%$ and $12.23 \%$ in larvae. Two-dimensional ordination plots of PCA analysis 172 showed a clear differentiation between CHC profiles in both species. The first factor divided 173 samples by species both in adults and larvae stages (Fig. 1). The second factor separated adults 174 by sexes, grouping females in the positive and males on the negative side of the axis (Fig. 1). 
175 The distribution pattern revealed larger differences in $\mathrm{CHC}$ composition between sexes in $N$.

176 baeticus than in E. jesusarribasi as well as a higher intraspecific variability in larvae of the latter.

177 In adults, MANOVA analyses showed significant differences in CHC composition between

178 species (Pillai's Trace $=0.99, \mathrm{df}=33, \mathrm{p}<0.001$ ), sex (Pillai's Trace $=0.93, \mathrm{df}=33, \mathrm{p}<0.001$ ) and

179 their interaction (Pillai's Trace $=0.95, \mathrm{df}=33, \mathrm{p}<0.001$ ), consistent with the patterns found by

180 PCA. The compound that contributed most to the differentiation between species was tricosane

181 (23C), only present in N. baeticus (Table 1). Methyl-alkane (27C) was the most contributing

182 compound in the differentiation between sexes, being only present in N. baeticus females.

183 In larvae, $\mathrm{CHC}$ profiles significantly differed between species $(\mathrm{F}=554.3, \mathrm{p}<0.001)$. The

184 compound that contributed most to such differentiation was an unsaturated compound (22C),

185 which was ten times more abundant in N. baeticus than in E. jesusarribasi.

186 Patterns in CHC classes

187 In general, methyl-alkanes were the most abundant class of CHCs in adults of both species, 188 representing between $41-59 \%$ of the total $\mathrm{CHCs}$ (Tables 1 and 2), while unsaturated compounds 189 were the dominant class in larvae $(>80 \%)$. Significant differences in abundance of all CHC 190 classes were found between larvae and adults in the two studied species, both in CHCs $\leq 20 \mathrm{C}$ 191 and $\mathrm{CHCs}>20 \mathrm{C}$ (Table S2).

192 Compounds shorter than 20 carbon atoms

193 Volatile CHCs were represented almost equally by n-alkanes and unsaturated compounds in 194 females of both species and in males of $N$. baeticus. In E. jesusarribasi males, the n-alkanes 195 represented the $100 \%$ of CHCs (Table 3). Methyl-alkanes were absent in both species. Despite 
196 these similar abundance patterns, the relative abundance of unsaturated and n-alkane compounds

197 significantly differed between species, being higher in N. baeticus than in E. jesusarribasi (Table

198 4). The relative abundance of these classes also differed between sexes showing a contrasting 199 pattern on each species (i.e. significant species $\mathrm{x}$ sex interaction, see Table 4). In larvae, 200 significant differences were also found between species in relative abundance of n-alkanes $201(\mathrm{~F}=43.27, \mathrm{p}<0.001)$ and unsaturated compounds $(\mathrm{F}=37.63, \mathrm{p}<0.001)$.

Compounds longer than 20 carbon atoms

203

204

205

206

207

208

209

210

211

212

213

214

215

216

Branched alkanes, especially methyl-alkanes, was the most abundant class in adults of both species, followed by n-alkanes and unsaturated compounds (Table 3). Significant differences in relative abundance of n-alkanes and branched alkenes were found between species and sexes (Table 4). Nebrioporus baeticus showed a higher abundance of n-alkanes compared with $E$. jesusarribasi and females of both species showed a significantly higher abundance than males. The opposite patterns were found for branched alkanes. In larvae, unsaturated compounds represented $84 \%$ in $N$. baeticus and $100 \%$ in E. jesusarribasi (Table 3), being this difference in abundance highly significant $(\mathrm{F}=8.60, \mathrm{p}<0.01)$.

\section{Discussion}

The CHC profile characterized for adults of the two species of saline water beetles studied here differed from that of other freshwater beetles, and showed common patterns to those generally attributed to adaptation to aridity in terrestrial Coleoptera. This points to an important role of cuticle permeability in driving tolerance to salinity and desiccation in these species. Comparison of CHC profiles between adults of $N$. baeticus and E. jesusarribasi and between life-stages and 
217 sexes within each species also revealed potential inter and intraspecific differences in cuticle

218 permeability likely related with differences in tolerance to osmotic stress.

\section{Interspecific variation in $\mathrm{CHCs}$}

220 We found marked differences in the patterns of CHC profiles between the saline studied species

221 and those previously reported for freshwater ones (Jacob \& Hanssen, 1986; Alarie et al., 1998).

222 In particular, if the CHC composition of $N$. baeticus is compared with that of other freshwater

223 species within the family Dytiscidae (Table 2), the cuticle of the saline species was characterized

224 by a higher abundance of longer chain branched alkanes, while freshwater species display a

225 relatively complex spectrum of $\mathrm{CHCs}$ with predominating amounts of unbranched components

226 (n-alkanes and unsaturated alkenes) (Table 2). Methyl-alkanes melt $10-30^{\circ} \mathrm{C}$ below n-alkanes

227 with the same chain length, depending on the location of the methyl branch (Gibbs \& Pomonis,

228 1995). The abundance of long-chain branched compounds and their interactions with other

229 alkanes compounds will determine the overall waterproofing properties of the surface lipids.

230 Accordingly, the CHC profile of the saline beetles studied here, dominated by more complex

231 compounds, is expected to confer them a more impermeable cuticle than that of freshwater ones.

232 This is likely an adaptation of insects living in temporary saline waters in arid climatic regions to

233 the osmotic stress imposed by water salinity and desiccation during seasonal droughts. Previous

234 studies have reported differences in water loss rates between beetle species with different saline

235 optima (Pallarés et al., 2016) or between freshwater and saline populations of corixids

236 (Cannings, 1981), supporting such hypothesis. Furthermore, a recent transcriptomic study in

237 Anopheles larvae has suggested that cuticle composition may be altered to deal with

238 osmoregulatory stress by decreasing permeability in saline water, as cuticle and cytoskeleton

239 genes were robustly induced at 40-50\% seawater salinities (Uyhelji et al., 2016). 
240 Some of the characteristics of $\mathrm{CHC}$ profiles described in the saline species studied here have

241 been also shown in terrestrial beetles adapted to aridity (Jacob \& Hassen, 1986; Lockey, 1979;

242 Lockey, 1988; Nelson \& Charlet, 2003). For example, the predominant class of CHCs in desert

243 Tenebrionidae, with an exceptionally thick and impermeable epicuticular wax layer, are

244 branched alkanes (Crowson, 1981), like in adults of the two studied species. In five desert

245 species from Arizona, no unsaturated hydrocarbons were detected in the cuticle (Jacob \&

246 Hassen, 1986) and the alkanes included both straight and branched chains, having the latter

247 generally more carbon atoms (Crowson, 1981). In the tenebrionid beetle Eleodes armata

248 LeConte, 1851 and a house cricket, Acheta domesticus L., 92\% of the branched compounds were

249 alkanes (Jackson \& Blomquist, 1976; Hadley, 1977). Thus, salinity could impose a selective

250 pressure on $\mathrm{CHC}$ profile of aquatic insects similar to that exerted by aridity in terrestrial species.

251 Long-chain methylbranched hydrocarbons could have an important role in limiting water loss by

252 osmosis or by transpiration through the cuticle.

253 The association between salinity, desiccation and CHC composition is also supported if the

$254 \mathrm{CHCs}$ of the two studied species are compared. A similar total number of compounds was

255 identified in both species suggesting a similar complexity of cuticle chemistry, but differences in

256 chain length and specific $\mathrm{CHCs}$ were found, pointing to a more impermeable cuticle in $E$.

257 jesusarribasi than in $N$. baeticus. Carbon chain length of CHCs ranged up to 36C in $E$.

258 jesusarribasi and $31 \mathrm{C}$ in $N$. baeticus. In addition, most of the compounds of E. jesusarribasi

259 ranged between 31-36C chain length. A high percentage of long-chain hydrocarbons has been

260 shown to confer impermeability to the cuticle in other arthropods (e.g. Hadley, 1976; Toolson \&

261 Hadley, 1977; Lockey, 1980; Gibbs \& Pomonis, 1995; Gibbs et al., 2003; Gibbs \& Rajpurohit,

262 2010). The contribution of $\mathrm{CHCs}$ in driving differences in stress tolerance between aquatic 
263 beetles needs to be further investigated, but the differences in cuticle permeability between the

264 two species inferred from our results are consistent with the higher desiccation resistance

265 (Pallarés et al., 2017), osmoregulatory ability and salinity tolerance (Pallarés et al., 2015) of E.

266 jesusarribasi compared to $N$. baeticus. Specifically, the average water loss rates under

267 desiccation conditions $(40 \% \mathrm{RH})$ was $4.04 \%$ of fresh mass $\mathrm{h}^{-1}$ in $N$. baeticus and $1.58 \%$ of fresh

268 mass $^{-1}$ in E.jesusarribasi (Pallarés et al., 2017).

269 Intraspecific variation in $\mathrm{CHCs}$

270 The different CHC profiles between larvae and adults within the two studied species were also

271 consistent with the expected differences in cuticle permeability between mature and immature

272 stages. Larvae had a remarkably lower number of CHCs with shorter chain length compared with

273 adults in both species. Furthermore, unsaturated compounds were the most abundant CHC class

274 in larvae, as expected according to their thinner, softer and more permeable cuticle if compared

275 with adults, and therefore less effective against water loss (Chapman, 1975). Adults showed a

276 lower abundance of unsaturated CHCs and a greater concentration of branched (their most

277 abundant $\mathrm{CHC}$ class) than n-alkanes. These compounds, with higher molecular weight and

278 melting temperatures (Gibbs \& Pomonis, 1995), may confer adults cuticle a higher resistance to

279 water loss (Chung \& Caroll, 2015), as required during flight dispersal.

280 Such differences in CHC complexity between adults and larvae reveal an important ontogenetic

281 modification of the cuticular lipids composition, in which chemical signature becomes enriched

282 as the individual is developing to adult, with the increase of long-chain compounds with higher

283 molecular weight. The main changes in $\mathrm{CHC}$ composition occur during the development from 
284 larval to adult stages, although sex dependent compositions also reflect a possible pheromonal

285 function of CHCs $\leq 20$ C, usually carried out by volatile compounds (Jacob \& Hanssen, 1986).

286 The CHC profile described here for two saline water beetles suggests that the cuticle of aquatic

287 coleopteran could have an important role in adaptation to salinity and desiccation. Studies

288 comparing cuticular lipids and water loss rates among related water beetle species would provide

289 a better understanding of how changes in lipid composition modulate cuticular transpiration in

290 these insects. The relationship between $\mathrm{CHC}$ composition and salinity tolerance also needs to be

291 further explored by comparison of CHC profiles between freshwater and saline species across

292 beetle lineages and the study of the plasticity of cuticle permeability in relation with changes in 293 salinity.

294 Acknowledgments

295 We thank José Rodríguez and technicians from the SAI (Servicio de Apoyo a la Investigación de 296 la Universidad de Murcia) for their technical support for GC-MS analysis. Thanks to María José 297 Jordán (IMIDA) for her advice in CHCs identification. We also thank Yves Alarie and one 298 anonymous referee for a constructive revision of our manuscript.

\section{References}

300 Addo-Bediako, A., Chown, S. L., \& Gaston, K. J. (2001) Revisiting water loss in insects: a large 301 scale view. Journal of Insect Physiology, 47(12), 1377-1388.

302 Alabi, T., Dean, J., Michaud, J. P., Verheggen, F., Lognay, G., \& Haubruge, E. (2011) Does 303 Tribolium brevicornis cuticular chemistry deter cannibalism and predation of pupae? Journal of 304 Insect Science, 11(1), 115. 
305 Alarie, Y., Joly, H. and Dennie, D. (1998) Cuticular hydrocarbon analysis of the aquatic beetle 306 Agabus anthracinus Mannerheim (Coleoptera: Dytiscidae). Canadian Entomologist, 130, 615307629.

Arcaz, A. C., Huestis, D. L., Dao, A., Diallo, M., Andersen, J., Blomquist, G. J., \& Lehmann, T. (2016) Desiccation tolerance in Anopheles coluzzii: the effects of spiracle size and cuticular hydrocarbons. Journal of Experimental Biology, 219(11), 1675-1688. usurpation of a nest by paper wasp parasites. Science, 272(5263), 889.

Beament, J. W. L. (1961) The waterproofing mechanism of arthropods: II. The permeability of the cuticle of some aquatic insects. Journal of Experimental Biology, 38(2), 277-290.

Benoit, J. B. (2010) Water management by dormant insects: comparisons between dehydration resistance during summer aestivation and winter diapause. Progress in Molecular and Subcellular Biology, Aestivation: Molecular and Physiological Aspects. (eds. C.A. Navas, J.E. Carvalho), pp. 209-229. Springer Berlin Heidelberg. Acromis sparsa (Coleoptera: Cassidinae) Mediate Arrestment Behavior of the Commensal Canestriniid Mite Grandiella rugosita. Journal of Chemical Ecology, 40(9), 996-1002. sexual and species identity in Drosophila melanogaster. Nature, 461(7266), 987-991. 
326 Blomquist, G. J. and Jackson, L. L. (1979) Chemistry and biochemistry of insect waxes.

327 Progress in Lipid Research, 17(4), 319-345.

328 Bradley, T. J. (2009) Animal Osmoregulation. Oxford Animal Biology Series, Oxford University

329 Press, New York.

330 Cannings, S.G. (1981) The influence of salinity on the cuticular permeability of Cenocorixa

331 bifida hungerfordi Lansbury (Hemiptera: Corixidae). Canadian Journal of Zoology, 59, 15053321509.

333 Carlson, D. A., Mayer, M. S., Silhacek, D. L., James, J. D., Beroza, M., \& Bierl, B. A. (1971)

334 Sex attractant pheromone of the house fly: isolation, identification and synthesis. Science 174, $335 \quad 76-78$.

336 Céspedes, V., Pallarés, S., Arribas, P., Millán, A., and Velasco, J. (2013) Water beetle tolerance 337 to salinity and anionic composition and its relationship to habitat occupancy. Journal of Insect 338 Physiology, 59(10), 1076-1084.

339 Chapman, R.F. (1975) The Insects: Structure and Function. Harward University Press, 340 Cambridge, UK.

341 Chung, H., and Carroll, S. B. (2015) Wax, sex and the origin of species: dual roles of insect 342 cuticular hydrocarbons in adaptation and mating. Bioessays, 37(7), 822-830.

343 Crowson R.A. (1981) The Biology of the Coleoptera. Academic Press, London.

344 Cuvillier-Hot, V., Cobb, M., Malosse, C., and Peeters, C. (2001) Sex, age and ovarian activity 345 affect cuticular hydrocarbons in Diacamma ceylonense, a queenless ant. Journal of Insect 346 Physiology, 47(4), 485-493. 
347 Gibbs, A. G. (1998) Water-proofing properties of cuticular lipids. American Zoologist, 471-482.

348 Gibbs, A.G., Chippindale, A.K. and Rose, M.R. (1997) Physiological mechanisms of evolved 349 desiccation resistance in Drosophila melanogaster. Journal of Experimental Biology, 200, $350 \quad 1821-1832$.

351 Gibbs, A. G., Fukuzato, F., \& Matzkin, L. M. (2003) Evolution of water conservation 352 mechanisms in Drosophila. Journal of Experimental Biology, 206(7), 1183-1192.

353 Gibbs, A., and Pomonis, J. G. (1995) Physical properties of insect cuticular hydrocarbons: the 354 effects of chain length, methyl-branching and unsaturation. Comparative Biochemistry and 355 Physiology Part B: Biochemistry and Molecular Biology, 112(2), 243-249.

356 Gibbs, A.G. and Rajpurohit S. (2010). Cuticular lipids and water balance. Insect Hydrocarbons: 357 Biology, Biochemistry, and Chemical Ecology. (eds. G.J. Blomquist and A.G. Bagnères). pp. 358 100-120. Cambridge University Press, Cambridge, UK.

359 Gołębiowski, M., Boguś, M. I., Paszkiewicz, M. and Stepnowski, P. (2011) Cuticular lipids of 360 insects as potential biofungicides: methods of lipid composition analysis. Analytical and 361 Bioanalytical Chemistry, 399(9), 3177-3191.

362 Gołębiowski, M., Maliński, E., Boguś, M. I., Kumirska, J. and Stepnowski, P. (2008) The 363 cuticular fatty acids of Calliphora vicina, Dendrolimus pini and Galleria mellonella larvae and 364 their role in resistance to fungal infection. Insect Biochemistry and Molecular Biology, 38(6), $365 \quad 619-627$.

366 Hadley, N. F. (1977) Epicuticular lipids of the desert tenebrionid beetle, Eleodes armata: 367 seasonal and acclimatory effects on composition. Insect Biochemistry, 7(3), 277-283. 
368 Hadley, N. F. (1978) Cuticular permeability of desert tenebrionid beetles: correlations with 369 epicuticular hydrocarbon composition. Insect Biochemistry, 8(1), 17-22.

370 Howard, R. W. and Blomquist, G. J. (1982) Chemical ecology and biochemistry of insect

371 hydrocarbons. Annual Review of Entomology, 27(1), 149-172.

372 Howard, R. W., and Blomquist, G. J. (2005) Ecological, behavioral, and biochemical aspects of 373 insect hydrocarbons. Annual Review of Entomology, 50, 371-393.

374 Jackson, L. L., \& Blomquist, G. J. (1976) Insect waxes. Chemistry and biochemistry of natural 375 waxes.(ed. P.E. Kolattukudy).pp. 201-233. Elsevier. Amsterdam

376 Jacob, J. and Hansen, H.P. (1986) Distribution and variability of cuticular hydrocarbons within 377 the Coleoptera. Biochemical Systematic and Ecology, 14, 207-210.

378 Jallon, J., Kunesch, G., Bricard, L. and Pennanec'h, M. (1997) Incorporation of fatty acids into 379 cuticular hydrocarbons of male and female Drosophila melanogaster. Journal of Insect 380 Physiology, 43, 1111-1116.

381 Kwan, L., \& Rundle, H. D. (2010) Adaptation to desiccation fails to generate pre-and postmating 382 isolation in replicate Drosophila melanogaster laboratory populations. Evolution, 64(3), 710383723.

384 Lockey K.H. (1979) Cuticular hydrocarbons of adult Alphitphagus bifasciatus (Say) and 385 Alphitobius diaperinus (Panz) (Coleoptera: Tenebrionidae). Comparative Biochemistry and 386 Physiology, 64B, 47-56.

387 Lockey, K. H. (1980) Insect cuticular hydrocarbons. Comparative Biochemistry and Physiology 388 Part B: Comparative Biochemistry, 65(3), 457-462. 
389 Lockey, K. H. (1988) Lipids of the insect cuticle: origin, composition and function. Comparative 390 Biochemistry and Physiology Part B: Comparative Biochemistry, 89(4), 595-645.

391 Maliński, E., Kuśmierz, J., Szafranek, J., Dubis, E., Poplawski, J., Wróbel, J. T., \& König, W. A. 392 (1986) Cuticular hydrocarbons of the Colorado beetle Leptinotarsa decemlineata Say. Zeitschrift 393 für Naturforschung B, 41(5), 567-574.

394 Millán, A., Sánchez-Fernández, D., Abellán, P., Picazo, F., Carbonell, J.A., Lobo, J.M. and 395 Ribera, I. (2014) Atlas de los coleópteros acuáticos de España peninsular. Ministerio de 396 Agricultura, Alimentación y Medio Ambiente, Madrid.

397 Millán, A., Velasco, J., Gutiérrez-Cánovas, C., Arribas, P., Picazo, F., Sánchez- Fernández, D. 398 and Abellán, P. (2011) Mediterranean saline streams in southeast Spain: What do we know? 399 Journal Arid Environment, 75, 1352-1359.

400 Nelson, D. R., \& Charlet, L. D. (2003) Cuticular hydrocarbons of the sunflower beetle, 401 Zygogramma exclamationis. Comparative Biochemistry and Physiology Part B: Biochemistry 402 and Molecular Biology, 135(2), 273-284.

403 Pallarés, S., Arribas, P., Bilton, D.T., Millán, A. and Velasco, J. (2015) The comparative 404 osmoregulatory ability of two water beetle genera whose species span the fresh-hypersaline 405 gradient in inland waters (Coleoptera: Dytiscidae, Hydrophilidae). Plos One 10, e0124299.

406 Pallares, S., Arribas, P., Cespedes, V., Millan, A., and Velasco, J. (2012) Lethal and sublethal 407 behavioural responses of saline water beetles to acute heat and osmotic stress. Ecological 408 Entomology, 37(6), 508-520. 
409 Pallarés, S., Botella-Cruz, M., Arribas, P., Millán, A., \& Velasco, J. (2017) Aquatic insects in a 410 multistress environment: cross-tolerance to salinity and desiccation. Journal of Experimental 411 Biology, jeb-152108.

412 Pallarés, S., Velasco, J., Millán, A., Bilton, D.T. and Arribas, P. (2016) Aquatic insects dealing 413 with dehydration: do desiccation resistance traits differ in species with contrasting habitat 414 preferences? PeerJ 4:e2382

415 Pattanayak, R., Mishra, G., Chanotiya, C. S., Rout, P. K., \& Mohanty, C. S. (2014) Does the 416 volatile hydrocarbon profile differ between the sexes: a case study on five aphidophagous 417 ladybirds. Insect Biochemistry and Physiology, 87(3), 105-125.

418 Rajpurohit, S., Hanus, R., Vrkoslav, V., Behrman, E. L., Bergland, A. O., Petrov, D. and 419 Schmidt, P. S. (2017) Adaptive dynamics of cuticular hydrocarbons in Drosophila. Journal of 420 Evolutionary Biology, 30(1), 66-80.

421 Rouault, J.D., Marican, C., Wicker-Thomas, C. and Jallon, J.M. (2004) Relations between 422 cuticular hydrocarbon (HC) polymorphism, resistance against desiccation and breeding 423 temperature; a model for HC evolution in D. melanogaster and D. simulans. Genetica, 120, 195424212.

425 Sánchez-Fernández, D., Calosi, P., Atfield, A., Arribas, P., Velasco, J., Spicer, J.I., Millán, A. 426 and Bilton, D.T. (2010) Reduced salinities compromise the thermal tolerance of hypersaline 427 specialist diving beetles. Physiological Entomology, 35, 265-273. 
428 Savković, U., Vučković, I., \& Stojković, B. (2012) The growth on different stored legume

429 species affects the profiles of cuticular hydrocarbon (CHC) in Acanthoscelides obtectus (Say).

430 Journal of Stored Products Research, 50, 66-72.

431 Stinziano, J. R., Sové, R. J., Rundle, H. D., \& Sinclair, B. J. (2015) Rapid desiccation hardening

432 changes the cuticular hydrocarbon profile of Drosophila melanogaster. Comparative

433 Biochemistry and Physiology Part A: Molecular \& Integrative Physiology, 180, 38-42.

434 Toolson, E. C. (1982) Effects of rearing temperature on cuticle permeability and epicuticular

435 lipid composition in Drosophila pseudoobscura. Journal of Experimental Zoology, 222(3), 249436253.

437 Toolson, E. C., \& Hadley, N. F. (1977) Cuticular permeability and epicuticular lipid composition 438 in two Arizona vejovid scorpions. Physiological Zoology, 50(4), 323-330.

439 Uyhelji, H.A., Cheng, C. \& Besansky, N.J. (2016) Transcriptomic differences between 440 euryhaline and stenohaline malaria vector sibling species in response to salinity stress. Molecular 441 Ecology, 25, 2210-2225.

442 Zhang, B., Xue, H. J., Song, K. Q., Liu, J., Li, W. Z., Nie, R. E., \& Yang, X. K. (2014) Male 443 mate recognition via cuticular hydrocarbons facilitates sexual isolation between sympatric leaf 444 beetle sister species. Journal of Insect Physiology, 70, 15-21.

445 Zuur, A. F., Ieno, E. N., Walker, N. J., Saveliev, A. A., and Smith, G. M. (2009) Zero-truncated 446 and zero-inflated models for count data. Mixed effects models and extensions in ecology with $R$. 447 (eds. M. Gail, K. Krickeberg,J. M. Samet, A. Tsiatis and W. Wong). pp.261-293. Springer, New 448 York. 
Table 1. Total number of cuticle hydrocarbons compounds and relative abundances of the main classes for adult (A, females and males) and larvae (L) life stages of the studied species. CHCs were analyzed in two separated groups in function of its chain length $(\leq 20 \mathrm{C}$ and $>20 \mathrm{C})$.

\begin{tabular}{|c|c|c|c|c|c|c|c|c|c|c|c|}
\hline \multicolumn{12}{|c|}{$\mathrm{CHCs} \leq 20 \mathrm{C}$} \\
\hline \multirow{3}{*}{ Species } & \multirow{3}{*}{$\begin{array}{c}\text { Life } \\
\text { stage }\end{array}$} & \multirow{3}{*}{ Sex } & \multirow{3}{*}{$\begin{array}{c}\text { Tota } \\
\quad 1\end{array}$} & \multicolumn{6}{|c|}{ Alkanes } & \multicolumn{2}{|c|}{ Unsaturated } \\
\hline & & & & \multicolumn{2}{|c|}{ n-Alkanes } & \multicolumn{2}{|c|}{$\begin{array}{c}\text { Methyl } \\
\text { branched }\end{array}$} & \multicolumn{2}{|c|}{$\begin{array}{c}\text { Other } \\
\text { branched }\end{array}$} & & \\
\hline & & & & $\mathrm{n}^{\mathbf{0}}$ & $\%$ & $\mathrm{n}^{\mathbf{0}}$ & $\%$ & $n^{0}$ & $\%$ & $\mathrm{n}^{\mathbf{0}}$ & $\%$ \\
\hline \multirow{3}{*}{ N. baeticus } & $\mathrm{A}$ & $\mathrm{F}$ & 7 & 4 & 48.04 & 0 & 0 & 1 & 1.96 & 2 & 50.00 \\
\hline & $\mathrm{A}$ & M & 7 & 4 & 54.33 & 0 & 0 & 0 & 0 & 3 & 45.66 \\
\hline & $\mathrm{L}$ & - & 10 & 3 & 14.86 & 1 & 2.7 & 3 & 8.22 & 3 & 74.22 \\
\hline \multirow{3}{*}{$\begin{array}{c}E . \\
\text { jesusarribasi }\end{array}$} & $\mathrm{A}$ & $\mathrm{F}$ & 11 & 4 & 45.97 & 0 & 0 & 4 & 11.88 & 3 & 42.15 \\
\hline & $\mathrm{A}$ & M & 3 & 3 & 100 & 0 & 0 & 0 & 0 & 0 & 0 \\
\hline & $\mathrm{L}$ & - & 11 & 5 & 20.81 & 0 & 0 & 2 & 7.2 & 4 & 71.99 \\
\hline \multicolumn{12}{|c|}{$\mathrm{CHCs}>20 \mathrm{C}$} \\
\hline \multirow{3}{*}{ Species } & \multirow{3}{*}{$\begin{array}{c}\text { Life } \\
\text { stage }\end{array}$} & \multirow{3}{*}{ Sex } & \multirow{3}{*}{$\begin{array}{c}\text { Tota } \\
\quad \text { l }\end{array}$} & \multicolumn{6}{|c|}{ Alkanes } & \multicolumn{2}{|c|}{ Unsaturated } \\
\hline & & & & \multicolumn{2}{|c|}{ n- Alkanes } & \multicolumn{2}{|c|}{$\begin{array}{c}\text { Methyl } \\
\text { branched }\end{array}$} & \multicolumn{2}{|c|}{$\begin{array}{c}\text { Other } \\
\text { branched }\end{array}$} & & \\
\hline & & & & $n^{0}$ & $\%$ & $\mathrm{n}^{\mathbf{0}}$ & $\%$ & $n^{0}$ & $\%$ & $n^{0}$ & $\%$ \\
\hline \multirow{3}{*}{ N. baeticus } & $\mathrm{A}$ & $\mathrm{F}$ & 43 & 11 & 25.37 & 17 & 51 & 5 & 17.28 & 10 & 6.35 \\
\hline & A & M & 50 & 13 & 18.22 & 17 & 42.51 & 10 & 34.17 & 10 & 5.10 \\
\hline & $\mathrm{L}$ & - & 15 & 2 & 8.57 & 3 & 5.62 & 2 & 1.34 & 8 & 84.47 \\
\hline \multirow{3}{*}{$\begin{array}{c}\text { E. } \\
\text { jesusarribasi }\end{array}$} & $\mathrm{A}$ & $\mathrm{F}$ & 45 & 8 & 16.04 & 13 & 43.32 & 16 & 35.46 & 8 & 5.18 \\
\hline & $\mathrm{A}$ & M & 43 & 7 & 13.05 & 19 & 47.09 & 10 & 32.31 & 7 & 7.55 \\
\hline & $\mathrm{L}$ & - & 9 & 0 & 0 & 0 & 0 & 0 & 0 & 9 & 100 \\
\hline
\end{tabular}




\begin{tabular}{|c|c|c|c|c|c|c|c|c|c|}
\hline \multirow[b]{3}{*}{ Habitat } & \multirow[b]{3}{*}{ Family } & \multicolumn{7}{|c|}{ ALL CHCs } & \\
\hline & & \multirow[b]{2}{*}{ Species } & \multirow[b]{2}{*}{ Sex } & \multicolumn{3}{|c|}{ Alkanes } & \multirow{2}{*}{$\begin{array}{l}\text { Unsaturat } \\
\text { ed }\end{array}$} & \multirow[t]{2}{*}{$\begin{array}{l}\text { Unidentifie } \\
\text { d }\end{array}$} & \\
\hline & & & & $\begin{array}{c}\text { n- } \\
\text { Alkane } \\
\text { s } \\
\end{array}$ & $\begin{array}{c}\text { Methyl } \\
\text { branched }\end{array}$ & $\begin{array}{c}\text { Other } \\
\text { branche } \\
\text { d } \\
\end{array}$ & & & \\
\hline \multirow{2}{*}{$\begin{array}{l}\text { Hypersalin } \\
\text { e }\end{array}$} & \multirow{2}{*}{$\begin{array}{l}\text { Hydrophilida } \\
\text { e }\end{array}$} & \multirow{2}{*}{ E. jesusarribasi } & $\mathrm{F}$ & 17.64 & 41.3 & 34.00 & 7.11 & & Present study \\
\hline & & & M & 13.38 & 46.83 & 32.38 & 7.41 & & " \\
\hline \multirow{2}{*}{$\begin{array}{c}\text { Mesosalin } \\
\mathrm{e}\end{array}$} & \multirow{2}{*}{ Dytiscidae } & \multirow{2}{*}{ N. baeticus } & $\mathrm{F}$ & 26.47 & 59.47 & 16.54 & 8.48 & & $"$ \\
\hline & & & M & 19.34 & 41.9 & 32.36 & 6.40 & & $"$ \\
\hline Freshwater & Dytiscidae & $\begin{array}{c}\text { Agabus } \\
\text { anthracinus }\end{array}$ & - & 46.9 & 25.9 & 0 & 27.1 & & Alaire et al. 1998 \\
\hline Freshwater & Dytiscidae & $\begin{array}{c}\text { Agabus } \\
\text { bipustulatus }\end{array}$ & - & 52.7 & 0 & 0 & 47.3 & & $\begin{array}{c}\text { Jacob and Hanssen } \\
1986\end{array}$ \\
\hline \multirow{2}{*}{ Freshwater } & \multirow{2}{*}{ Dytiscidae } & Dytiscus & $\mathrm{F}$ & 78.5 & 3.4 & 5.6 & 8.3 & 4.2 & " \\
\hline & & marginalis & M & 36 & 2.7 & 1.8 & 59.5 & & $"$ \\
\hline Freshwater & Dytiscidae & Ilybius angustior & M & 43 & 1.5 & 1.8 & 51.6 & 2.1 & $"$ \\
\hline
\end{tabular}


452 Table 3. Species, sex and its interaction effects on the relative abundance of the main cuticle

453 hydrocarbons $(\mathrm{CHCs} \leq 20 \mathrm{C})$ in adults.

\begin{tabular}{ccccc}
\hline Class & & df & F value & P value \\
\hline \multirow{3}{*}{ n- Alkanes } & Species & 1 & 11.92 & 0.001 \\
& Sex & 1 & 26.80 & $<0.001$ \\
& Species*Sex & 1 & 13.30 & $<0.001$ \\
& Residuals & 34 & & $<0.001$ \\
\hline \multirow{2}{*}{ Unsaturated } & Species & 1 & 51.23 & $<0.001$ \\
& Sex & 1 & 94.11 & $<0.001$
\end{tabular}

454 df: degrees of freedom

455

456 Table 4. Species, sex and its interaction effects on the relative abundance of the main cuticle

457 hydrocarbons classes (CHCs $>20 \mathrm{C})$ in adults.

\begin{tabular}{ccccc}
\hline Class & & df & F value & P value \\
\hline \multirow{2}{*}{ n-Alkanes } & Species & 1 & 28.88 & $<0.001$ \\
& Sex & 1 & 13.01 & $<0.001$ \\
& Species*Sex & 1 & 2.67 & 0.12 \\
& Residuals & 34 & & $<0.001$ \\
Branched alkanes & Species & 1 & 19.15 & $<0.001$ \\
(Methyl-alkanes and & Sex & 1 & 17.97 & 0.17 \\
others) & Species*Sex & 1 & 1.89 & \\
& Residuals & 34 & & 0.73 \\
& Species & 1 & 0.12 & 0.74 \\
Unsaturated & Sex & 1 & 0.11 & 0.19 \\
\hline
\end{tabular}




\section{Residuals $\quad 34$}

458 df: degrees of freedom

459 Figure 1. Projection of principal component analysis (PCA) factor scores with the first two 460 PCA factors of the quantitative patterns of cuticular hydrocarbons (CHCs) in adults and larvae of

461 Nebriopus baeticus and Enochrus jesusarribasi. 


\section{Adults}

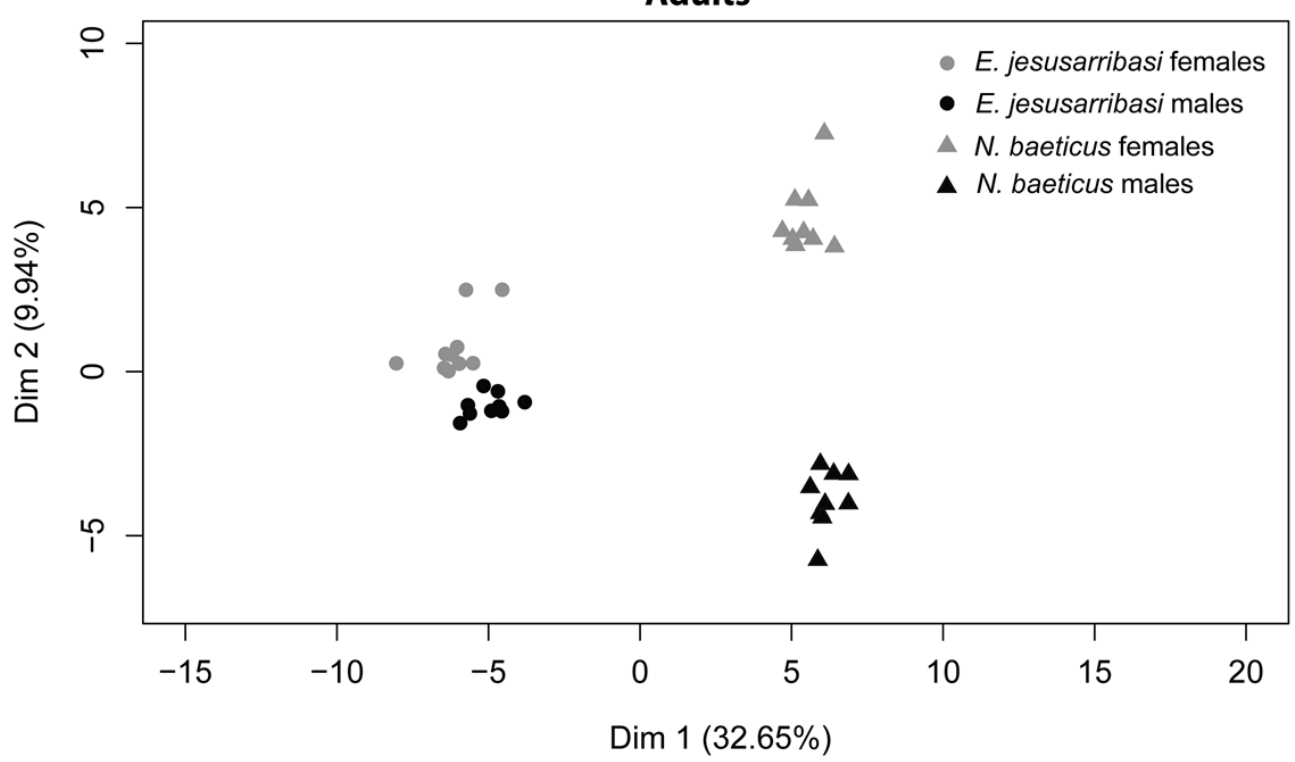

Larvae

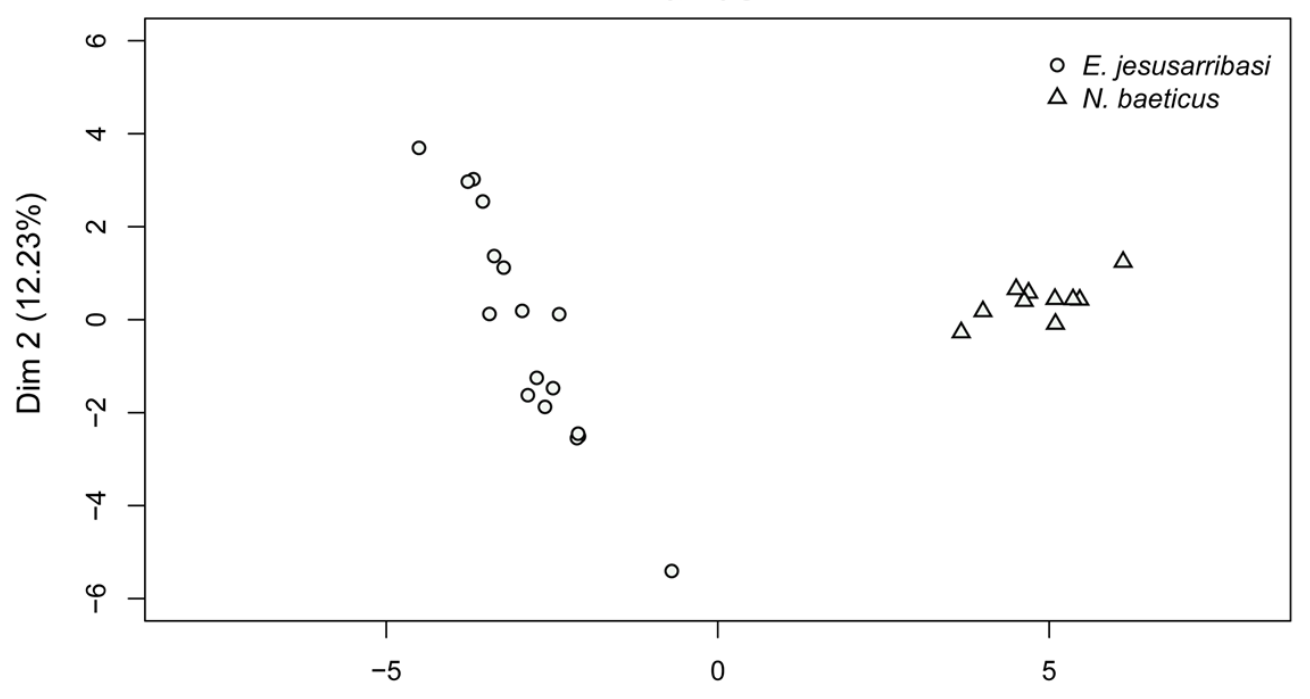

$\operatorname{Dim} 1$ (46.83\%) 